\title{
2 \\ POLICY CHALLENGES FOR SMALL ECONOMIES IN A GLOBALISING WORLD
}

\author{
L. Alan Winters
}

This chapter is a sequel to work I conducted recently with Pedro Martins on the costs of doing business in small economies (Winters and Martins 2004, 2005). Somewhat to my surprise, this research, based on specially collected data, showed that, ceteris paribus, manufacturing and tourism faced significantly higher business costs in small isolated economies than elsewhere. It would be absurd to proclaim the estimates we produced to be unassailable, but their size and the fairly thorough review they received in the November 2004 issue of the World Trade Review leave me convinced that they are qualitatively correct.

The next question, therefore, is what should we-and they-do about these excess costs? That is the issue taken up in this chapter. It discusses international trade policy, industrial policy, governance and government for small isolated economies, and trade preferences, aid and migration as responses by the international community. There appear to me to be no easy solutions for the small countries themselves, but there certainly are helpful steps that many could take on trade policy and governance. For the world community, I do not see how we can avoid ultimately talking about migration.

\section{THE COSTS OF SMALL SIZE}

The starting point for this study is the results of Winters and Martins' $(2004,2005)$ studies showing that the private costs of manufacturing activity are considerably higher for small economies than for larger ones. 
Their work collates data on business costs in 92 economies drawn from four distinct sources. The largest contribution is from the Economist Intelligence Unit (EIU) which surveys 54 medium-sized and large countries twice a year. The remaining surveys were commissioned by the Commonwealth Secretariat for the Winters and Martins study from three regional organisations covering various (mostly small) economies: Imani Capricorn in Africa, the Caribbean Community in the Caribbean and the Pacific Islands Forum in the Pacific. All these surveys date from mid 2002. The questions covered transport costs on exports and imports, the costs of utilities, the wages of different types of labour, taxes and rents as continuous variables, plus labour shortages, utility reliability and policy regimes on a categorical basis.

Having collected the data, Winters and Martins test empirically for the existence of relationships between the different business costs and country size (population, and occasionally aggregate GDP). As well as descriptive statistics, they run simple linear regressions (OLS) on size and other appropriate variables for the continuous variables, and ordered logit equations for the categorical variables in which respondents classify their country in one of several categories. Given the regression results, they calculate the cost disadvantage for four specimen countries, chosen to represent micro (12,000 inhabitants), very small (200,000), 'threshold' (1.6 million) and small economies (4 million) relative to their median country, which has approximately 10 million inhabitants. ${ }^{1}$

The population values used for these representative countries correspond to Anguilla, Vanuatu, Botswana, Singapore and Hungary, respectively. These calculations suggest that there are significant penalties to small size in most of the costs analysed (Table 2.1). In a second exercise, Winters and Martins (2004) aggregate the cost disadvantage factors to estimate the competitive disadvantages of small economies in three example industries (electronic assembly, clothing and tourism) in which small countries seem likely to have comparative advantage and hence export potential. Using data on the importance of particular costs in the overall cost of supplying exports to the world market (production and transportation costs), they weight together the cost disadvantage factors to calculate the excess costs of exports from small economies. These are presented in Table 2.2.

Given the uncertainties of the data it seems that small countries (of which the exemplar is Singapore, population 4 million) are not severely handicapped in comparison with Winters and Martins' fictional median country and neither 
is the threshold country. However, it is equally clear that for the very small or micro countries (Vanuatu, population 200,000; and Anguilla, population 12,000), the size disadvantages are huge. Moreover, if these cost premia can not be passed onto customers (that is, if small economies have to sell their goods and services at world prices), the small economy can only export if some part of the production process is willing to bear the costs by accepting lower returns than it would reap in the median economy. When Winters and Martins convert the cost inflation factors into such income penalties, they are huge for very small and micro economies. In most cases the data suggest that capital

Table 2.1 Summary of cost disadvantages

(\% deviation of costs from those in the median economy)

\begin{tabular}{|c|c|c|c|c|}
\hline Area of cost & Micro & Very Small & Threshold & Small \\
\hline Airfreight average $e^{a}$ & 31.8 & 4.1 & -1.8 & -1.7 \\
\hline Seafreight average & 219.6 & 70.5 & 20.5 & 9.1 \\
\hline Unskilled wages average & 60.1 & 31.6 & 13.6 & 6.6 \\
\hline Semi-skilled wages average & 22.4 & 12.1 & 5.8 & 2.6 \\
\hline Skilled wages average & 38.0 & 20.3 & 8.9 & 4.3 \\
\hline Telephone average (marginal costs) & 98.5 & 47.2 & 19.1 & 9.0 \\
\hline Electricity (marginal costs) & 93.1 & 47.0 & 19.7 & 9.4 \\
\hline Water (marginal costs) & - & - & - & - \\
\hline Fuel average & 53.8 & 28.3 & 12.3 & 5.9 \\
\hline Personal air travel average & 115.7 & 56.8 & 23.3 & 11.0 \\
\hline Land rent average & -3.5 & -17.2 & -14.2 & -8.9 \\
\hline
\end{tabular}

Note: 'Average' denotes that the reported estimate is the mean of several measures of the costs concerned. Source: Central case from Winters, L.A. and Martins, P.M.G., 2004. 'When comparative advantage is not enough: business costs in small remote economies', World Trade Review, 3(3):347-83.

Table 2.2 Cost inflation factors (\% by which target country costs of supplying exports exceed median country costs)

\begin{tabular}{llccc}
\hline & Micro & Very small & Threshold & Small \\
Industry & 36.4 & 14.3 & 5.0 & 2.7 \\
Electronic assembly & 36.3 & 14.3 & 5.1 & 2.7 \\
Clothing & 57.5 & 28.5 & 11.9 & 6.2 \\
Hotels and tourism & & & & \\
\hline
\end{tabular}

Source: Winters, L.A. and Martins, P.M.G., 2004. 'When comparative advantage is not enough: business costs in small remote economies', World Trade Review, 3(3):347-83. 
would earn negative returns if it were invested in a micro economy and had to bear all the cost of the inefficiencies itself. Similarly, even if wages were zero in a micro economy, total costs in manufacturing would still exceed world prices.

Finally, Winters and Martins present some data to see if small states have worse policies than other countries, using variables such as bank interest rates, corporate tax rates and import and export duties. These show no strong evidence of size effects. Interest rates seem to be lower in small economies, but there is compelling proof of neither higher tax rates for business nor higher import/ export duties than in larger economies.

\section{TRADE POLICY}

A first reaction to the high costs faced by manufacturing in small, isolated economies is that, in order to compensate for these extra costs and for the costs of international trading, these countries need the right to protect their industries. $^{2}$ This is completely misguided. The problem is not that imports can get in too easily but the very opposite. Adding barriers to trade will exacerbate, not relieve, problems of smallness. Even where local industries could be successfully established behind tariff walls, there is nothing in the observation of transaction costs or genuine 'excess costs' of inputs to suggest that such an approach would be economically beneficial. Simple theory has long shown that following comparative advantage maximises real income. The costs identified by Winters and Martins do not change this-they merely show that for some countries comparative advantage may entail no trade and that for some, possibly the same, countries, maximum income might not be adequate.

A related response has been to suggest subsidising business activities, or perhaps investment, in order to overcome the cost disadvantages of smallness. There are many arguments in the policymaking literature for subsidising business in an economy. I do not generally agree with them, but, even if I did, smallness adds nothing to them. If you would not subsidise business in a large economy, neither should you do so in an equivalent small one, for precisely the reasons outlined in the previous paragraph. Smallness does not generally introduce marginal distortions that need to be countervailed, but an overall feasibility constraint. If income is insufficient when you maximise it, it will certainly be insufficient when you do not; and in the absence of the market failures usually adduced to justify industrial policy, subsidising manufacturing puts you in the latter category. 
It is useful to make these points graphically. First, transactions costs with the rest of the world affect the offer curve that a small open economy faces. In Figure 2.1, if the rest of the world will trade at prices P'QP', the broken line, a small country (which has to pay its own transactions costs) faces an offer curve of PQP, the solid line, where Q represents the point of no trade. PQP lies below P'QP' everywhere except Q. Regardless in which direction the country trades, it has to finance the transactions costs on both legs of the journey. Assuming that for each good these costs are the same in both directions and that, without loss of generality, they have to be paid in Y, we can derive PQP as follows.

Suppose the slope of P'QP' is $\mathrm{p}$, so that one $\mathrm{X}$ trades for $\mathrm{p}$ units of $\mathrm{Y}$. Consider a trade that swaps one $\mathrm{X}$ for $\mathrm{pY}$ on world markets and that transactions costs are $a$ units of $Y$ per $Y$ traded and $b$ units of $Y$ per X traded $(a, b<1)$. If our country exports $X$, the supposed trade would take the world to point $A$, but because we have to pay $(a p+b)$ units of $Y$ for transport, etc., our country achieves

Figure 2.1 The transaction-cost modified offer curve

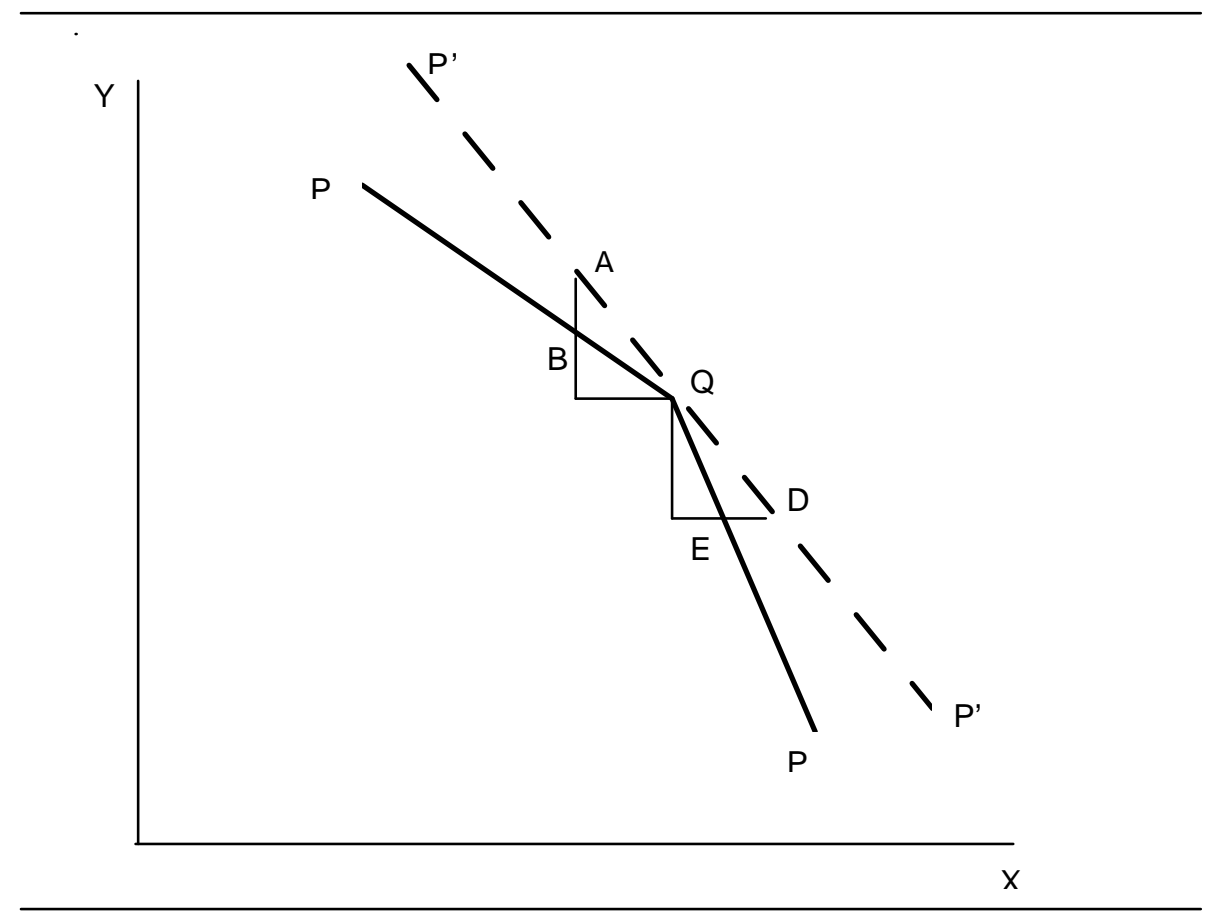


only point B with $1-(a+b \mathrm{p})$ units of $\mathrm{Y}$. Now suppose that we export $\mathrm{pY}$ to place the rest of the world at $\mathrm{D}$, we still have to find $(a \mathrm{p}+b)$ again, and supposing that this is deducted from imports of $\mathrm{X}$ we receive only $1-(a+b / \mathrm{p})$ units of $\mathrm{X}$, that is, we achieve point $\mathrm{E}$.

Given PQP we can derive the consumption possibility frontier (CC) for our small country by sliding it along FF the production possibility frontier in Figure 2.2, and tracing the northeasterly-most points. Figure 2.2 shows three possible locations for $\mathrm{PQP}$ corresponding to three regimes. With production at $\mathrm{Q}_{1}$ we have comparative advantage in $\mathrm{X}$ and export it to consume at, say, $\mathrm{C}_{1}$. With production at $\mathrm{Q}_{3}$, the opposite applies - we export $\mathrm{Y}$ to consume at, say, $\mathrm{C}_{3}$. Along the middle range, in which the slope of FF lies between those of the branches of PQP we do not trade, and hence consume at the production point. (Because PQP has linear segments there is no virtue in producing to the left of $\mathrm{Q}_{1}$ - the consumption locus would lie inside that shown. If PQP were continuous and concave, that would not apply, but then we would not be a small country for the world price ratio would be changing as our country's trade changed).

Given CC we can find the optimal consumption and production pair using a (well-behaved) social welfare function. Note that at all along CC the marginal rates of transformation and substitution (the slopes of $\mathrm{FF}$ and the corresponding piece of CC, respectively) are equal, so that there is no case for trade intervention or for production subsidies or taxes. For example, if free trade took us to $Q_{1}$, a production subsidy on $\mathrm{Y}$ would move us to the left and the consumption locus would lie unambiguously inside the CC shown. For standard reasons, a tariff would be even worse, for it would move the consumption locus inwards and choose a non-optimal point along it.

Similarly, consider starting at $\mathrm{Q}_{2}$. A production subsidy to either $\mathrm{X}$ or $\mathrm{Y}$ would move us towards $\mathrm{Q}_{3}$ or $\mathrm{Q}_{1}$, respectively, but would not normally induce any trade because an indifference map preferring $\mathrm{Q}_{2}$ to all other points on CC would prefer consuming at $\mathrm{Q}_{3}$ to all points along the segment $\mathrm{Q}_{3} \mathrm{C}_{3}$. An export subsidy, however, could move us to a point along that segment but again, fairly obviously from the figure, that would be even worse than settling at $Q_{3}$.

The discussion so far presumes that FF is the true social production possibility frontier. That is, although our small economy may face inefficiencies in the transformation of primary factors into final goods and services deriving from its small scale, these do not represent domestic distortions. Thus while, for example, inefficiencies in power generation may make electricity more expensive 
Figure 2.2 The consumption possibility locus with transaction costs

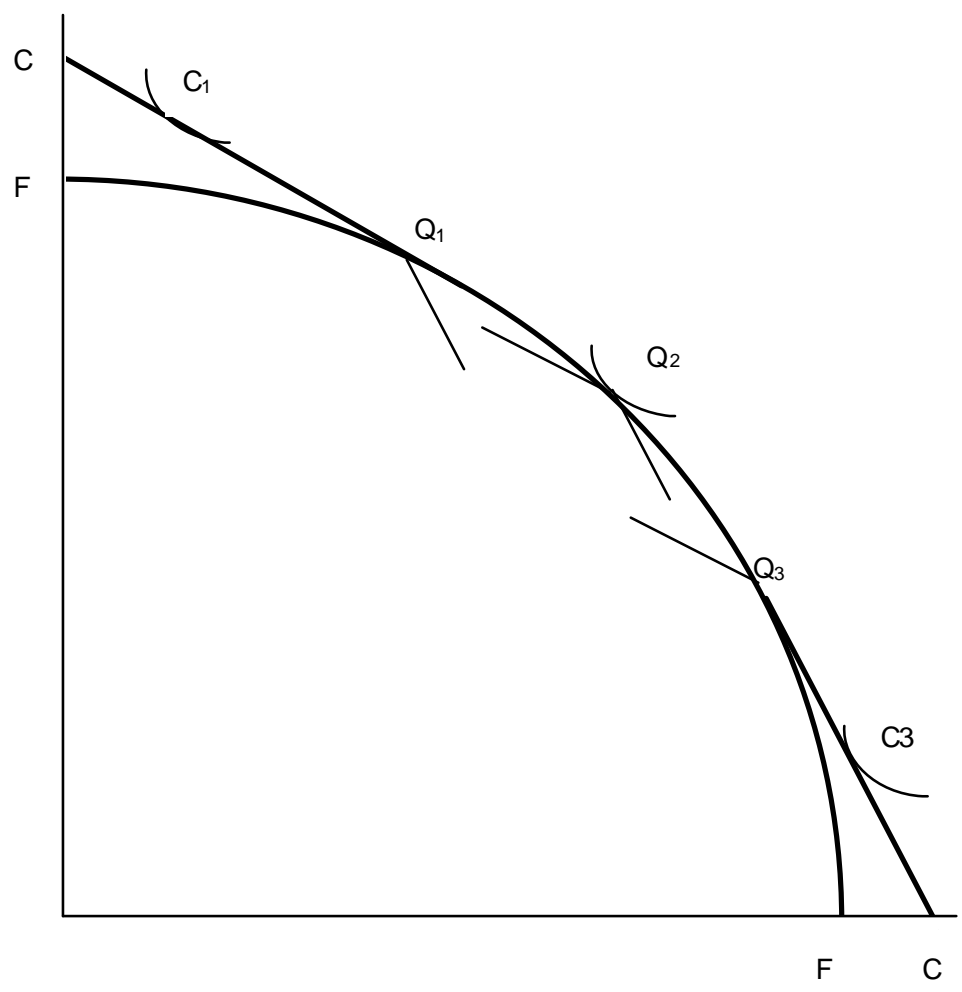

than in the median country, we assume that they are both unavoidable and apply equally to all production sectors. If these conditions are not met, an appropriate policy intervention could push FF (and hence CC) outwardsbut precisely how would depend on the factor and/or electricity intensity of sectors and the nature of the intersectoral inequality to be corrected. Under these circumstances, standard second-best theory means that if the fundamental distortions cannot/will not be addressed directly, then a production or trade intervention could be welfare-enhancing.

The introduction of transactions costs does not fundamentally change the standard welfare analysis. Thus, if inefficiencies in electricity production lead to the under-production of, say, X, policies that boost the output of X-subsidies or tariffs_could be desirable. The proposition is not that any subsidy or tariff 
would help, however, only that there may be levels that do so. As with large economies, the challenge is finding the distortion and introducing an intervention at the socially optimal level. In small societies this may be even more difficult than in larger ones because of the difficulties of finding disinterested parties and the generally greater power of special interests in small economies (see below). Moreover, the fact remains that addressing the distortion directly is first best, and that if the 'excess costs' are actually non-distortionary, policy interventions will be harmful. For example, if power is unavoidably expensive, small countries do not have comparative advantage in energy-intensive manufacturing. Subsidising such manufacturing to compensate for high power costs would be bad economics - it would increase the use of relatively costly inputs and divert other factors from better uses elsewhere in the economy.

What cost disadvantages in small countries are distortions and what are just 'natural' handicaps? Scale effects in utilities are natural, but the market power emerging from having few suppliers may be distortionary. In these cases, however, subsidising the use of monopolised inputs is very unattractive from a distributional perspective. Monopolists inflate their incomes by restricting their supply. Subsidising sectors that use their output adds insult to injury by further enhancing their incomes at the expense of taxpayers. Far better is to regulate them more effectively. The same analysis applies to other produced inputs, although for tradable goods (and services such as banking) local monopoly is constrained by the threat of imports even if the latter do face high transactions costs, so the problem is likely to be limited.

The excess transactions costs that small and remote countries face on international trade may well also result from monopoly power-of the liner cartel, for example-but these are essentially given for an individual small economy and so are 'real' for the purposes of domestic policy formulation. Similarly high, possibly unreasonable, risk premia on international borrowing are basically part of a small country's environment.

One area of evident difficulty for small isolated economies is human capital. For very high skills, they will never be satisfactory locations-for example, for nuclear physicists, hot-shot property lawyers and leading baseball players. Thus at this level, their shortage is natural. At lower levels of skill, however, the skill shortages — which emerge very clearly in Winters and Martins' findings—may be endogenous, and hence may represent distortions. I do not think we know enough about this and should $\log$ it as an area for future research. 
A common response to the costs of small scale is to argue that market size should be increased by regional agreements with neighbours. While the intention is entirely correct, the implementation of such agreements is frequently flawed because they are drawn too narrowly. Specifically, if regional agreements are restricted to trade policy — that is, regional trading arrangements (RTAs), which merely provide mutual trade preferences-they are almost certainly doomed. Where the partner country is large, the small country typically just ends up adopting the partner's internal price structure. To the extent that this equals world prices, well and good, but to the extent that the large country has protection, its distortionary effects are merely visited also on the small country. This could offer income gains by giving to the small country higher prices for its exports, although in asymmetric, large-small, regional agreements access to the most protected markets is frequently withheld. The European Union, for example, controls small partners' access to its agricultural markets and (until recently) textile and clothing markets. It also, however, means that the small country has to pay protection-inflated prices for many of its imports from the large partner (trade diversion) rather than lower world prices.

Where the RTA partner is small, the outcome is almost inevitably economically costly. The polar small-partners model of an RTA—see, for example, Winters (2000) or Panagariya (2000)—generates only losses. Small partners cannot satisfy each others' demands, imports continue from the rest of the world, and since neither their prices nor the tariffs they face change, the internal prices of imports do not change, so there is no scope for (welfare-enhancing) trade creation. Trade diversion, on the other hand, continues unabated. Schiff (2001) has modified the polar model, but the basic message is not fundamentally changed.

The problem with RTAs is not that trade with neighbouring countries is free, but that with other countries is restricted. To enlarge effective market size (and to be able to purchase from the cheapest sources) free trade with neighbours typically comes a poor second to free trade with everyone.

It is worth noting that all this analysis presupposes that the small economy has no particular advantage (location, for example) or niche market. The former essentially gives it a cost advantage in some sectors, while the latter essentially allows it to charge higher prices than its competitors. Such favoured countries will fare well and all small countries should aim to achieve such status. The analysis of this chapter is, however, predicated on the reasonable assumption that not all will, although it certainly does not imply that none will. 


\section{POLICY AND GOVERNANCE}

Winters and Martins (2004) suggest that small countries do not have significantly worse policies than other countries in the few dimensions that they could measure: tariffs, export subsidies and direct taxes. ${ }^{3}$ This is only a partial list of policies and misses entirely all aspects of governance, so it is worth exploring these dimensions further. Unfortunately we do not have any comprehensive and objective datasets on the dimensions we require, but partial sources do not suggest large differences between large and small countries. Briguglio et al. (2005) suggest that over 1999-2003 the mean CPIA (Country Policy and Institutional Assessments) scores for 34 small and 102 larger economies were not far different. ${ }^{4}$ Small countries were assessed as relatively stronger on financial stability, banking regulation, transparency and governance, but weaker on product and factor markets.

A second source of policy/governance data is the Doing Business surveys (World Bank 2004), which for various business-related costs and facilities compares 14 small economies with 131 larger ones. Again the differences in means are not particularly great.

Despite the similarity of means in these measures, however, the small countries should not be complacent. There are wide variances and in a number of cases we know that small countries perform very badly-for example, the incidence of crime in some Caribbean countries and governmental stability in some Pacific ones. More importantly, it is not difficult to imagine models in which economic activity, especially investment, is more sensitive to governance problems in small economies than in larger ones. For example, small economies offer no advantages in terms of local market opportunities, so there is no offset to any shortcomings in production conditions. ${ }^{5}$ Thus, in terms of policy priorities, improvement in governance and in the costs of doing business they must rank fairly highly.

One of the major challenges that small economies face in addressing their problems of governance is the difficulty in small polities of avoiding capture by special interests. In small undiversified economies, interest groups are relatively larger and have to deal with only a small number of opponents. This makes the exercise of influence stemming from social status or current economic power easier, with the result that change becomes much more difficult (this argument is due to James Madison in the Federalist Paper No. X of 1788). In addition, in small economies the costs of favouring special interests cannot be hidden 
but fall squarely, obviously and relatively heavily, on the other groups. This could make decision-making more transparent and rational but is equally likely to make it divisive and costly. Add to this some natural social segmentation, such as that on ethnic grounds, and the problems can become overwhelming.

A second, politically incorrect but statistically inevitable, challenge for small countries, is leadership. If leaders are selected on merit (in whatever dimension), no matter what the underlying distribution of talent, leaders from small countries are likely to be less able than those from larger ones. It is difficult to quantify the cost of the expected shortfall because we don't have well-defined talent-to-performance or performance-to-outcome functions, but its existence is undeniable.

Alesina and Spolaore (2003) explore the consequences of the size of countries/ economies by comparing the benefits of size with the costs of trying to meet the conflicting demands of more sub-populations with different preferences as country size increases. Among the benefits of size they note are

- market size, which is mitigated by openness, the effects of which, in turn, are eroded by the transactions costs of trade explored above. This is discussed in the section 'trade policy'

- the mutual insurance that regions in large economies provide for each other

- defence and strategic advantages

- the fixed costs of government.

Government involves some activities with fixed costs such as foreign representation and policy design, and others with strong economies of scale, such as defence and exercising strategic influence. Large countries can spread these more widely than can smaller ones, and Alesina and Spolaore offer empirical evidence on the extra costs of governments for small countries. They find a significant cross-country correlation between population and the share of government consumption in GDP, suggesting that a 1 per cent increase in population reduces the consumption share by around 0.012 percentage points ceteris paribus. The effect is strongest for current expenditures excluding transfers, but is entirely absent for defence.

The only realistic answer to these problems of government cost is to combine with other countries in providing these services - to economise on the costs of economic management and/or statehood. Andriamananjara and Schiff (2001) and Schiff and Winters (2003) argue strongly that by combining various 
functions of government small states can both economise on costs and, possibly, exert a greater influence on their environments. Such efficiencies are not sufficient to overcome all the disadvantage faced by most small countries-for example, combining the entire population of the organisation of East Caribbean states still leaves the resultant 'state' well within the definition of 'small'. But there is undoubtedly a case for seeking such efficiency gains as part of the answer. I also note that in the cases where smallness appears not to matter-small European nations such as Luxembourg, Liechtenstein and Andorra for example-the secret appears to be to integrate more or less seamlessly with the neighbouring large countries.

The last observation is important for small states. Combining to produce government services does not mean establishing regional authorities and then maintaining local capabilities to influence and monitor those authorities. It means a genuine pooling of sovereignty with no local shadowing - , for example, countries within a country maintain no foreign or security policy establishments. This is no mean step-it is essentially political union-and so it relies on mutual trust and on sound regional institutions which ensure that local imperatives are adequately addressed. To many residents of small countries this may seem a high price to pay, but in fact it is no higher than that 'paid' by, say, the Victorians and Queenslanders in forming Australia or, given the very small sizes involved, Yorkshiremen and Lancastrians combining in England. That it is a 'price' is exactly the point made by Alesina and Spolaore-political independence entails economic costs. This perspective raises the question of whether, if political independence is the fundamental problem for small countries, the 'price' should be paid by their residents or by the rest of the world. If it is paid by the latter, we are essentially subsidising smallness and should expect more of it to occur.

One innovative proposal from Briguglio et al. (2005) is that, even if small countries retain their policymaking, they could subcontract many of the administrative functions of governments, such as issuing driving licenses and paying pensions. This may allow some savings although there may be a tradeoff between savings and the choice of contractor. Combining these functions among several small countries would offer some savings (and could be made approximately reciprocal in a mercantilist sense if each function went to a different economy), but would probably be less cost-efficient than subcontracting to a major economy with very large economies of scale. In the 
latter, the service would be a net import, which would have to be paid for by transaction-cost-intensive exports, but provided that the price of foreign exchange were set properly, comparing prices would allow the right decision to be made.

Finally, under this heading we should note one apparent advantage of governmental fragmentation. The current organisation of world society confers some fixed advantages of statehood which are worth more per head to small than to large economies. These include a vote at the United Nations and the WTO and the right to issue (read 'sell') passports, flags of convenience, banking licences and internet addresses. To be politically incorrect again, these advantages mostly entail either the management of external costs or the creation of public goods which impinge, very roughly, equally on everyone in the world (at least in an expected value sense). Thus it is not clear that allocating such rights equally to each state is optimal. Nonetheless, many small states currently make a living from such sales and if we seek to constrain this by international agreements about banking or shipping standards, we will further increase the pressure to support small state incomes in some other way.

\section{INFRASTRUCTURE, HUMAN CAPITAL AND SERVICE EXPORTS}

A second way of addressing the excess cost of manufacturing identified by Winters and Martins is to think in terms of services exports. Among the more successful small economies, niche tourism and financial services are major sources of export earnings. These are less handicapped by the excess costs of physical movement than are goods. Success in these areas clearly requires strong governance performance-especially security and regulatory ability, respectively-but if these conditions pertain they are quite promising. I do not believe, however, that they can address all of the income deficits of small economies.

First, the required capital has to be provided. The risk premia faced by small countries are typically higher than one might expect given their governance and economic circumstances. Partly, this may be ignorance on the part of the lenders, but it also reflects real risk phenomena. Even setting aside the apparent higher vulnerability of small remote economies to physical shocks (World Bank 2000a) the lack of diversity in small economies increases the risk of economic disruption.

Second, even if capital can be provided for infrastructure, many of the cost disadvantages of small economies in Winters and Martins are on current 
expenditure. For example, even if service exports are independent of transportation disadvantages, imports are not. Considering that ships and planes need to travel back as well as towards a small economy, the savings entailed in service exports may not be that great.

Third, the most favourable case for infrastructure-led salvation is probably communications links. If these are excellent and cheap, the electronic provision of services may become competitive, such as data input, software, tele-services. Even in 'electronic services', however, personal contacts are important (see Chanda 2003), so small remote economies will still be disadvantaged by their high travel costs and long travel times.

Fourth, many service exports require human capital. This not only requires investment but also constant honing, typically through contact with customers and rivals abroad. This, in turn, raises the spectre of migration. Winters and Martin (2004) identify serious shortages of skilled labour in small remote economies both in terms of relatively high wages and reported shortages even among current producers. The reasons for this are not hard to find. Up to a point, the returns to skills are a function of the size of the market that is served, merely in terms of covering the fixed cost of skill acquisition. In addition, there are typically economies of agglomeration for skilled activities such as specialisation, stimulation, and the transfer of knowledge.

While some skilled workers can certainly be retained in small economies, not least because of the more pleasant lifestyle, their productivity is for these reasons unlikely to be of the highest order, and the higher the skill level, the greater the deficit.

The 'brain drain' represents a huge challenge to many small countries. The latest data in Docquier and Marfouk (2005), for example, show that 86 per cent of Guyanese and 83 per cent of Jamaicans with higher education live abroad. These are, of course, countries with governance challenges, but the figures are high even for more successful societies-36 per cent for the Bahamas and 61 per cent for Barbados

Some have suggested using bonds to encourage students (or even workers) to return from abroad in order to recoup the costs of their education to their home small economies. This may make sense in Singapore where skills can be properly rewarded in the domestic economy, but for smaller less successful economies it is likely to amount to little more than the ex post private finance of education. That is, people will merely pay the bond in order to leave. Given 
the enforcement difficulties of such bonds, my own preference in these circumstances would be to provide basic education free of charge-as something one generation provides to another-and have private financing of higher education. The latter would need to be supplemented by higher salaries at home (to fund repayment but made possible by savings in the public funding of universities) and also loans and bursaries for poorer households.

I have argued elsewhere that liberalising the temporary movements of labour within the world economy - mode 4 of the GATS — can generate huge economic gains (Winters et al. 2003a, 2003b). This could be a key factor for very small economies, essentially allowing residents to earn abroad but live and consume at home. Temporary workers from small countries would still be at a disadvantage relative to those from larger ones-they would face higher transport costs, less effective networks for finding jobs and easing migratory strains, and higher consumption costs at home. However, particularly if they had preferential access — such as the guaranteed quotas that New Zealand offers some Pacific islanders - they may be able to 'out compete' other sources of labour. Just as with trade preferences, however, the sustainability of the mobility preferences would be a question-mark.

If temporary mobility is to be a long-term solution, there would need to be considerable trust that the receiving larger country would honour the quotas. It would also require trust that that country would encourage (enforce) the temporariness of the labour contracts and not actively screen temporary migrants for permanent places. If these conditions were met, I believe temporary mobility would indeed be a viable means of maintaining some small economies, including providing the incentives for education.

\section{SUBSIDISING THE SMALL COUNTRY: TRADE PREFERENCES AND AID}

The previous section proposed policy approaches to smallness that involved larger countries as well. This section pursues the logic further and considers explicit or implicit subsidies for small countries' trade. It differs from the analysis in the section 'trade policy' in that the subsidy is now paid by the external large country (or world community). Thus, while the same distortion is introduced to our small country as before, it is now partially, fully or overfully compensated by a transfer from abroad. The net effect could be an improvement in welfare, although it need not be. 
The current tariff preferences for small countries' exports allow them to sell at industrial country markets' tariff-inclusive prices rather than at world prices. This source of rent has historically been very important-as, for example, with banana or tuna exports to the European Union (EU) or clothing exports from the Caribbean to the United States. The problems are first that other developing countries have become more hostile to these preferences, as with Latin American challenges to banana preferences and East Asian challenges to those on tuna, and that the more legalistic regime of the WTO makes them harder to defend than they were under the General Agreement on Tariffs and Trade (GATT). Second, as donors discover new favourites, the preferences of the old are eroded. Consider Pakistan's recent advantages under the textile quotas and the way in which the North American Free Trade Agreement (NAFTA) and now African Growth and Opportunity Act (AGOA) reduced the advantages of the Caribbean Basin Initiative (CBI). Third, the benefits of preferences are declining anyway as industrial countries move, or are moved, to liberalise their trade regimes. In all these cases, as Winters and Martins show, very small economies face large income penalties as rents are reduced.

An alternative route could be for industrial countries to subsidise small country trade explicitly_either their exports or their imports, or both. This would require conscious policy shifts in the major capitals and also derogations from WTO agreements. This could have the effect of eventually-with large enough subsidies-turning the offer curve in Figure 2.1 from concave to convex, with the upper leg steeper than the lower one. Provided that the subsidies outweighed the transactions costs, the small economy would always trade and could always do better than under 'costless' but unsubsidised trade. In Figure 2.3, P'QP' is the consumption possibility locus under 'costless' free trade, while with export subsidies the locus would be CDC, where points such as $\mathrm{C}_{1}$ or $\mathrm{C}_{3}$ would be chosen (with corresponding production points $\mathrm{Q}_{1}$ and $\mathrm{Q}_{3}$, respectively).

An alternative route would be straight income transfers (as recommended by de Vries 1975). Here the money would presumably go to the government, which would distribute it somehow. This would avoid the production distortion entailed in the trade subsidies, saving resources, but would pose even greater problems so far as governance and incentives to produce were concerned. In either case, one of the main issues for the recipients would be the security of such transfers. As I noted above, I believe that they would need to be permanent to cover excess costs on current transactions and so could not be dressed up 
merely as transitional financing to encourage structural adjustment. ${ }^{7}$ Preferences are declining and subsidies are always vulnerable, but unless there were reasonable confidence that they would continue, all manner of short-term rent-seeking behaviour would arise.

A second issue, especially for simple income subsidies (aid) and also for the large remittance flows received by some small remote economies is the cancer of aid-dependence. Perpetual and unconditional income flows appear to be very destructive to the productive economy and eventually to society. There is nothing wrong per se in not working or investing if the money keeps flowing, but it appears that at the same time as work habits decline so do various other social habits, especially if traditional societal structures have been undermined. Particularly problematic appears to be youth unemployment and boredom. Hence one observes social malaise not only in dependent island economies of the Pacific, but in the native American reservations in the United States, in pension-dependent societies in South Africa and in some oil states.

Figure 2.3 Consumption locus with externally funded export subsidies

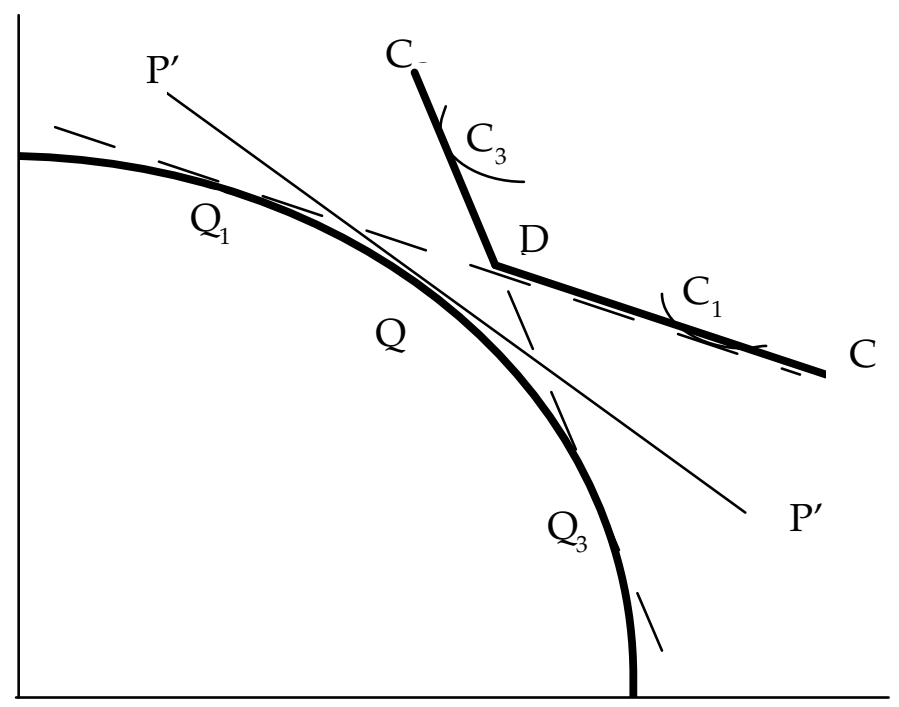


Explicit subsidies to micro and very small economies raise their own very particular political challenges. Specifically, many of the cost disadvantages identified by Winters and Martins must also apply to isolated parts of larger countries. These disadvantaged regions are often subsidised via regional policies, as for example, in the United Kingdom, Europe more generally and China. However, if small economies were permitted to have export subsidies, one would need to argue explicitly why this privilege should not be extended to parts of larger economies, for if it were it would probably fatally undermine subsidies discipline in the WTO. The reason is not hard to formulate, but it may be uncomfortable: within a country, people can move out of uneconomic locations. Ultimately the world must face the possibility that if the current preferences that small countries receive are eroded and their incomes can not be maintained in other ways, many of their inhabitants will seek to move abroad.

\section{CONCLUSION}

The preceding observation makes the trade-off for the rest of the world plain. On the other hand, the moral case for international policies to support small remote economies is not overwhelming at present. They are not particularly income-poor by world standards nor particularly stagnant, and once one accounts for their attractions as location and the attractions (to many of us) of smaller societies, they do not seem too badly off. True the developed countries have helped to create their current production structures, and changes in developed country policies have contributed to the concerns about their futures, but this is at most a transitional issue. Moreover, many small economies do not appear to be maximising their prospects for essentially governance-related reasons. Plenty of commentators argue that with sufficient focus small economies could find viable activities and that nothing focuses the mind like the money running out. Thus a case can certainly be made that permanent support for small economies is inappropriate.

On the other hand, I do not believe that all small countries will remain economically viable. Their excess costs are a serious handicap and in an ever more closely integrated and sophisticated world economy their disadvantages are likely to grow. For sure some will thrive by good luck or sound judgment, but left to themselves, others are likely to decline sufficiently that humanitarian imperatives arise, and their problems do become those of the world community. 
If we let them get to this stage, economic rescue will be very expensive and population movement will become almost inevitable. Thus it seems to me that if we believe that small economies do not warrant international support we need to be prepared eventually to let their people move elsewhere if incomes fall too low to compensate for the advantages of small society living. Particularly if we limit the relaxation in immigration policy to the micro and very small economies the effects will be very small in aggregate. Around 3.12 million people ( 0.05 per cent of the world's population) live in countries of below 200,000 population, 6.31 million $(0.10$ per cent $)$ in those below 400,000 and 28.20 million $(0.45$ per cent) in those below 1.5 million population.

\section{ACKNOWLEDGMENTS}

The findings, interpretations and conclusions expressed in this note are entirely those of the author and do not necessarily reflect the views of the Board of Executive Directors of the World Bank or the governments they represent. I am grateful to Ross Garnaut, workshop members and participants in a seminar at the Australian Treasury for comments on the earlier draft of this paper. They are not responsible for its remaining shortcomings. Thanks are also due to Audrey Kitson-Walters and Zenaida Kranzer for logistical help.

\section{NOTES}

1 'Threshold' derives from the now fairly standard threshold for defining small economies of 1.5 million people.

2 On transactions costs, the argument is implicitly that, since high costs curtail exports, policy is required to curtail imports and help producers exploit their domestic markets.

3 We tried and failed to collect data on VATs and budget deficits.

4 The Country Policy and Institutional Assessments (CPIA) are assessments by World Bank staff based on a variety of sources and are being published from July 2005 onwards.

5 Consider how companies persisted with production in China, despite the many instances in which they were unable to protect their assets from local predation. I have not been able to locate any formal tests of the hypothesis that governance matters more for small countries.

6 Alesina and Spolaore observe that, once global or regional institutions guarantee access to foreign markets, the main cost of smallness is removed and we see greater tendencies towards fragmentation.

7 Finance to encourage diversification in small economies has not been very successful in the past. 